\title{
Technology for social work education
}

\author{
Tom Hopkins* and David Colombi** \\ *Institute of Health and Community Services, Bournemouth University \\ ** Centre for Human Service Technology, University of Southampton
}

The intention of this paper is to examine aspects of the role of information technology in social work education in relation to existing developments within an international context. conceptual issues concerning the application of CAL to the teaching of social work, and the implication of these issues for the development of integrated teaching modules in Interpersonal Skills and Research Methods, together with some of the practical issues encountered and solutions being adopted. The context for the paper is joint work by the authors as members of the ProCare Project, a partnership between Southampton and Bournemouth Universities, and part of the UK Government-funded Teaching and Learning Technology Programme (TLTP) in Higher Education. ProCare is developing courseware on Interpersonal Skills and on Research Methods for use in qualifying-level Social Work and Nursing education. While the emphasis is on the social work version of the Interpersonal Skills module, limited reference is made to the nursing component and the differential approaches that proved necessary within the subject areas under development.

\section{Social work and IT developments}

The development of technology in social-work education is set not only in the broader context of the use of technology in higher education generally, but also in the parallel context of the use of technology in social work practice. The latter is important for a subject area with two primary characteristics:

the need to acquire not just academic knowledge but also professional expertise and understanding of the aims, methods and values of social work;

a strong emphasis on practical preparation for work in social work agencies, which is expressed through the universal use of practice placements within agencies as a major component of social-work professional education and training.

Within contemporary social work practice, it is possible to identify several broad themes concerning the use of new technology: 
a low level of overall penetration into the work of social work agencies;

a primary focus on developing basic client information systems;

a preoccupation with the needs of managers and local and central government for financial and statistical data used for accountability and policy purposes.

As a consequence, there has until recently been little expectation by employers that those completing professional social-work training will be computer literate, although that situation is now changing. Those who do acquire such skills may experience frustration at the limited opportunities within agencies to develop and apply them in their work with clients.

For social work courses the issues are, then, primarily about how technology is used for educational purposes. However, for some educators there is a secondary objective of contributing to initiatives which may indirectly help to reshape social-work practice through diffusion, example and opportunity. The barriers for social-work education include many shared with other disciplines, but also some that are unique, or at least less common. Those that are familiar, applying across most or all disciplines, may be characterized as:

Structural: organizational resistance and/or antipathy towards new technology, arising from an unwillingness to contemplate organizational changes which the use of new technology requires.

Developmental: failure or unwillingness of course planners, managers and instructors to consider the potential of new technology in relation to curriculum needs and requirements; identifying the place of Computer-Assisted Learning (CAL) in the curriculum and developing the competence and confidence of teachers to use CAL and adapt teaching styles to a CAL environment.

Conceptual: confusion about the nature of the activity - whether CAL, Computer-Based Learning (CBL) or Computer-Assisted Instruction (CAI). The term CAL is used here with an emphasis on learning rather than instruction; and on computer assistance rather than the more fully entrenched role implicit in CBL.

Practical: availability of and access to required technology, quality software and appropriate computer teaching environments (including educational, technical and administrative supports); the second aspect depends on the extent to which software is designed to be used entirely by students working alone, or as part of a teaching and/or other shared learning experience.

Philosophical/ideological: individual resistance by staff, through apathy, anxiety or hostility, including the 'not invented here' syndrome; also, collective resistance by academic (and some professional) groupings to new technology having other than a minor, adjunctival role to play in education for human-service professions.

Personal: individual resistance by academics and practitioners to new technology in professional education and training, largely out of fear of job change, relocation or loss; these views are shared by some students who see the introduction of new technology as less attractive than conventional instruction, and which may require more effort on their part (see Hopkins, 1996). 
Less familiar barriers include:

Professional: the imprecise nature of the knowledge base of social work that makes it less amenable to computerization than more structured and precise knowledge-based systems, such as science, law or medicine.

Ethical: issues of client confidentiality, together with concerns about the extent to which computers may be perceived as dehumanizing or undermining the quintessentially personal interactions which characterize much social work.

On the positive side, there is an international co-operative endeavour to contribute, primarily at an academic level, but also at a practitioner level, to change. This work finds its strongest collective expression though a series of international conferences known as HUSITA (Human Services Information Technology Applications), and through the work of the European Network for Information Technology in the Human Services (ENITH). These endeavours provide a means of meeting, sharing and networking, and the focus for publication of conference papers and other texts, such as international comparative studies (Colombi, 1993; Steyaert 1996).

The educational dimension to this work is an important one amongst other aspects that include concerns about the needs of social-work practitioners, service users and other citizens, combined with emphasis on ethical themes of empowerment, disability, discrimination and confidentiality (Glastonbury and LaMendola, 1993). The educational dimension includes development of simulation software in the areas of child protection (Schoech, 1996) and discrimination (Seabury, 1993), and information software in the areas of child protection (Child Care Information System from SSRADU), care management (Unlocking Care Management from CCETSW), social work literature (CareData from NISW) and social work and technology (Social Work and Information Technology from CHST).

Within the social work education dimension to this co-operative work there are, inevitably, both similarities and differences. The differences are exemplified by development within the Netherlands, Belgium and some other continental European countries of the concept of 'social informatics' (Visser, 1996). In these European contexts, the concept is dealt with as a taught course on the curriculum (Roosenboom 1993), rather than the more experiential introduction to using technology as an educational medium across all aspects of the curriculum, found in British and North American higher education.

\section{CAL for social work: some conceptual issues and concerns}

In comparison with other forms of non-traditional instruction - print-based, video, audio etc. - CAL has yet to make much impact on social-work education delivery for reasons outlined earlier. Together with other issues beyond the scope of this paper, these constitute a formidable set of barriers and obstacles which advocates of CAL for socialwork education must address. However, at the very centre of the debate about the use of CAL for social-work education and training lies a much more fundamental set of issues. Put simply, these are concerned with the ability of CAL to offer and deliver a teaching and learning experience which is as effective as more established modes. 
In order to challenge some of the criticisms which are made of CAL for social-work education, it is necessary first to understand something of the conventional practices of mainstream social-work education, and the values, attitudes and beliefs that underpin them. Based on a view that the nature of social work is contested and contestable, and that these complexities and ambiguities must be reflected in the curriculum, the main characteristics of contemporary educational practice in this field are that:

most learners already possess some relevant knowledge and skills;

teaching and learning must be, at least in part, experiential (real or simulated);

education and training methods should be learner-centred;

learners should be involved in identifying and managing their own learning needs;

instruction should include, wherever possible, elements of group-based learning;

staff should act primarily as facilitators and enablers of learning.

While not each and every class or study-session of a social work course will incorporate every aspect of the above, learners and staff will, overall, share a view of the education and training process to which this description closely corresponds. It is not difficult to see that a central tenet of contemporary social-work education is interaction, between teacher and learner, and amongst learners themselves.

Thus, any new instructional medium has not only to contend with the set of macro- and mezzo-level issues outlined at the beginning of this section, but must then prove itself in relation to a set of micro-issues specifically concerned with the nature and experience of teaching and learning. Put at its simplest - and most challenging - new modes of education and training must be able not only to match the content of conventional offerings but also their process and outcomes.

This would be challenge enough to CAL if its use was to be simply adjunctival, complementing or supplementing mainstream methods of instruction. The literature of CAL's recent history in higher education generally, and specifically in social work, shows this is its primary function; staff recommend rather than require student use. However, increasingly British higher-education funding support for CAL development is linked with notions of 'greater efficiency', which translates into cost-savings, particularly of teacher-learner contact time.

Thus, CAL for social-work education and training must, if it wishes to be taken seriously as a mainstream method of instruction, be designed primarily as a replacement for, rather than a supplement to existing delivery. Put another way, to be acceptable to both educators and learners, CAL must offer and deliver learning experiences at least as effective as those currently in use.

In trying to respond to this challenge, the temptation is to look first for technological solutions, for example by designing CAL materials that are sophisticated, incorporating sound and graphics, possibly video, perhaps in CD-ROM format, in the belief that these will in some unspecified way compensate learners for the absence of more conventional features of teaching and learning, particularly that of engaging with the content of the material. Yet, most social work departments currently lack access to the computer 
hardware required to run such programs, or on such a small scale that use of CAL material could never be more than adjunctival.

While multimedia features play an increasingly important role in CAL, greater technological sophistication alone will not redeem a program which lacks a clear and coherent teaching and learning strategy. Effective software requires interactivity both at the level of design of how imaginatively users can access and be presented with material, and at the level of how they are helped to respond to the content. Thus the most appropriate and fruitful response to the challenge of developing CAL materials for social work lies initially in a deeper understanding of what constitutes effective teaching and learning, and how the content, structure and process of CAL materials can be designed to deliver it.

\section{Developing the interpersonal skills module}

We turn now to the specific work within the ProCare project team of creating social work and nursing modules in the field of Interpersonal Skills (IPS) under the headings of Design and Structure, Content, Functioning and Implementation.

\section{Design and structure}

Curriculum design within UK higher education has, in recent years, become an extremely complex task. Where once curriculum content and structure were the sole province of academics, a range of influences, some competing, now play a significant part in shaping the planning of courses and programmes (for a detailed consideration of this area, see Hopkins, 1995). Of most significance here are:

the near-universal modular restructuring of higher-education courses;

the shift from an input-driven to an outcomes-led curriculum model;

attempts to create interdisciplinary and interprofessional education.

The first of these led to an early decision that CAL materials would be designed to fit the modular course structures now commonly found in higher education throughout the UK (for a discussion in relation to social work, see Storan, 1992). The decision called for materials to be designed within a context of prescribed module sizes, expressed in credit points, with indications of likely overall 'student effort hours' required for successful completion. This would assist social-work tutors who wished to consider the use of ProCare materials as part or whole replacement for existing teaching arrangements. The second factor was significant for program design in that it required CAL materials to state clearly and consistently the objectives of each module (and in turn, each unit and session), and how the learner would achieve them.

The third factor is of greatest significance for this paper, in that it speaks to the professional contexts of social work and nursing, and thus, by implication education and training in preparation for it. It has two major strands, which briefly may be characterized as follows:

that it is both possible and desirable to blur or erase existing boundaries between professional groupings, with the objective of creating interprofessionally-skilled 
practitioners (see Weinstein, 1994); that a) may be achieved while simultaneously embracing the increasing shift towards 'specialism' within professional practice.

In designing the Interpersonal Skills and Research Methods modules, these two factors manifested themselves in the following ways.

Interprofessionalism. Our early belief that it would be relatively easy to design materials for interprofessional use was challenged by educators and students alike. This led us to consider a choice between separate versions for Social Work and Nursing, or a combined program offering choices about specific Social Work or Nursing case examples. In practice, it proved necessary to develop separate versions for Interpersonal Skills, given the more fundamental differences involved between the two professions, allied to practical issues about developing and evaluating the source materials. For Research Methods, the differences between the professions were less critical and a single module approach was developed which allowed the user to choose at any stage between being offered social work or nursing case examples,

Specialism. Here, the central question for development concerned whether to meet needs of specific groups in and related to the two professions, such as staff working in residential settings; in special educational needs; in the fields of disability and psychiatry; or in voluntary and private-sector settings. A decision was made to provide materials of a generic nature, while earmarking them for future development once basic versions of the programs are stabilized.

\section{Content}

With the primary focus on content in mind, in seeking to create a framework for development, the following elements of curriculum philosophy and design were conceived of as central:

what are the overall aims of the module?

what are the objectives of the module, expressed as competencies to be achieved?

what knowledge and skills must learners acquire in order to become competent?

what knowledge and skills might learners already possess, and how can they be accessed?

what might constitute an effective teaching and learning process?

what might constitute an effective module structure?

Discussions of these issues amongst project staff resulted in a design for the IPS module consisting of eight units, which together cover the key phases of contact between social workers and their clients, viz:

Communication and IPS

Making Contact

Assessment

Planning

Implementation 
Maintaining Contact

Endings

Evaluation

This structure is complemented by two key tools, described later, of a Notepad facility and a Skills Bank. Most of the eight units above consist of two CAL sessions; each session, following a short introduction and objective setting stage, includes the following elements, in a similar sequential format.

Context activity. These require learners to begin each session by identifying, through recall and review, past and/or current relevant knowledge and practice skills. This activity also helps orientate the learner towards the new information and other activities encountered within the session (see Figure 1).

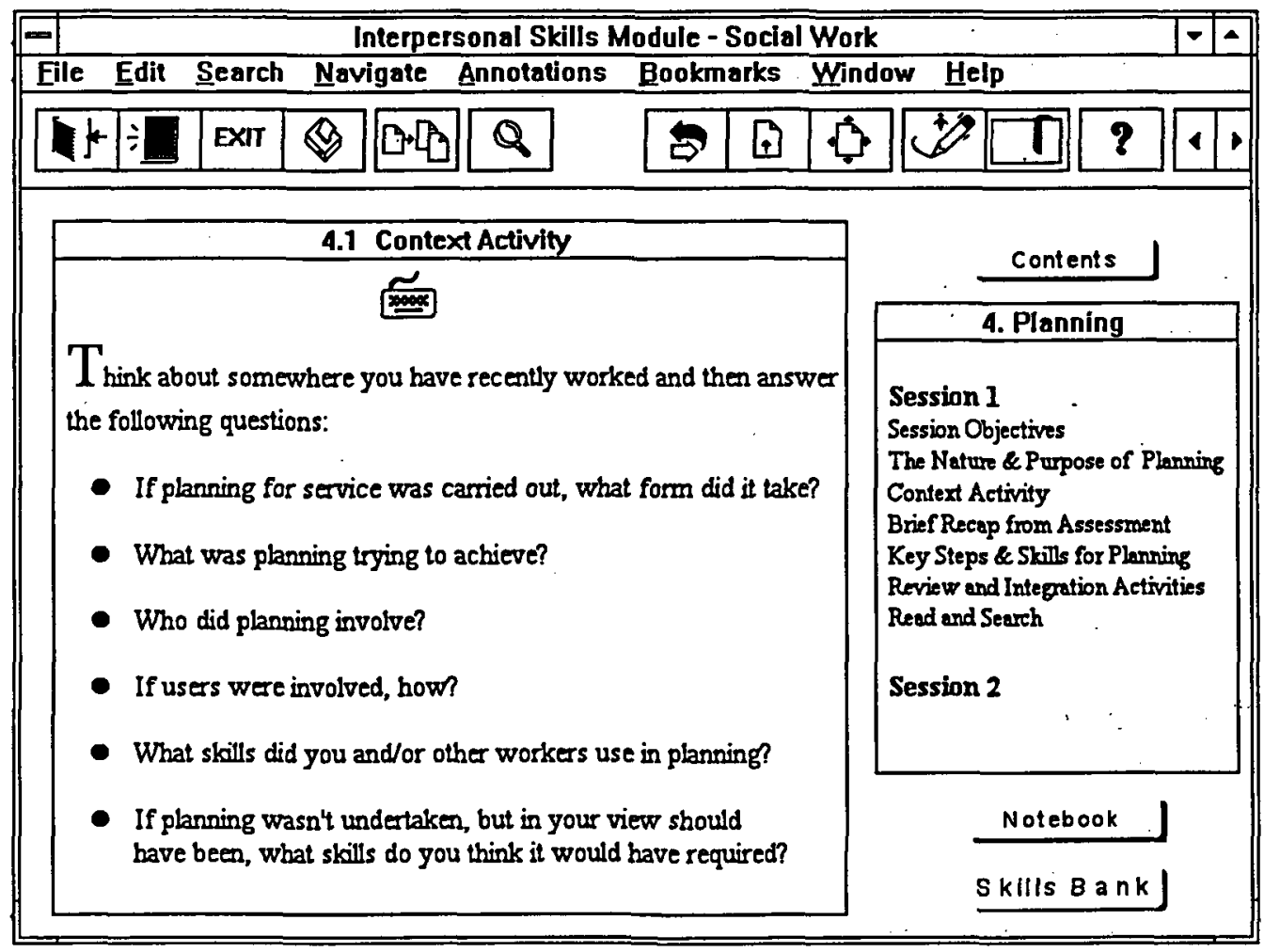

Figure 1

Teaching Content. Information is presented in the form of major theoretical perspectives, key concepts, critical issues, contrasting viewpoints, etc. Much as in conventional teaching, it seeks to engender a sense of enquiry; critical thinking, and a willingness to.live with the ambiguities of professional practice (see Figure 2). 


\begin{tabular}{||l|l|l|l||}
\hline \multicolumn{3}{|c|}{ Interpersonal Skills Module - Social Work } \\
\hline File Edit Search Navigate Annotations
\end{tabular}

Figure 2

Review and Integration Activity. As its name suggests, this activity requires students to work at integrating existing and new learning through a practice-focused exercise such as the one in Figure 3.

Integration and Preparation Activity. Students are required to use the learning they have acquired during the session (and preceding ones) in preparation for real or simulated practice. Learners may be asked to undertake a range of tasks, including:

searching for evidence of specific interpersonal skills embedded in case dialogue;

planning for handling hypothetical interactions between workers and clients;

proposing alternative ways of dealing with complex interpersonal communications between clients and workers;

undertaking self-assessment of their own interpersonal skills, and identifying ways and means of improving them.

As the above illustrates, within the IPS module, structure and process are inextricably linked. Laying out the various elements of the curriculum strategy helps learners to develop a familiarity with the way in which the module works in educational terms, while also recognizing that all effective learning involves a process and outcome. Students are also prepared for their use of the module by a User's Guide which explains, in a non- 


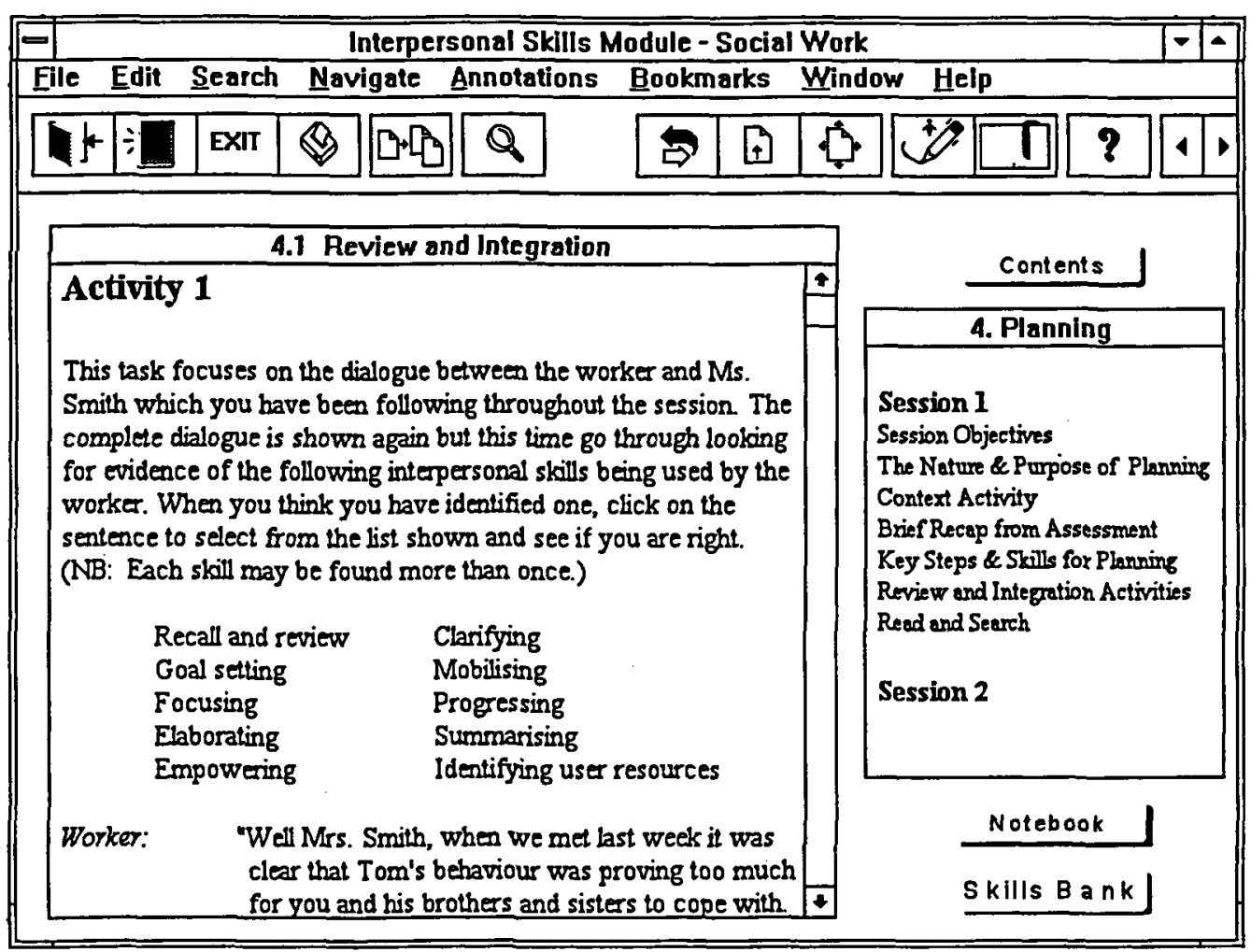

Figure 3

jargonistic way, how the modules were conceived, how they are intended to work, and how to obtain help if problems, either technical or educational, are encountered.

\section{Functioning}

The way that software functions is shaped by a variety of factors including the specification of computers available to users, the programming and design time and skills available, the program size planned, and the authoring system(s) and environment used. The first of these factors was discussed earlier as a significant limiting factor for implementation in most social-work educational settings. Other key aspects considered here are navigation, hypertext, special tools and authoring system(s).

Navigation. The requirements were that users have a clear overall view of the program, and their current position and progress, combined with freedom to move around the program at will rather than along pre-set paths. This presents dilemmas in that the knowledge incorporated in each program is incremental and cumulative so that 'naive' users need to understand earlier sections to gain from later ones. That the material has a logical progressive structure is, however, no reason to provide a straitjacket; just as books allow users to browse, flip, dip and peruse as well as to read through from start to finish, so should CAL.

Hypertext. Use of hypertext facilities provides definitions, explanations, answers to questions and reference information in the form of pop-up notes. It is also used for 
making links between different sections of the program so that users can move from one topic of interest to another in a non-linear fashion. Hypertext is one aspect of interactivity in which the user makes decisions and choices rather than just being a passive respondent.

Special tools. The Notepad facility referred to earlier allows students to undertake written tasks, to make notes, and to copy key materials for use in assignments and seminars. It is context-sensitive with relevant text already included, and notes can be stored, printed or transferred to a word processor of choice. The Skills Bank is an index of interpersonal skills referred to in the program with a brief description of each. Students are helped to understand that most skills are of a generic nature, with applicability in a variety of practice situations. Other interactive features include demonstrations of specific humanservice tools and techniques, such as Ecomaps and Genograms.

Authoring systems. Given that both modules are largely text-based and offer less scope that many other subjects for visual representation, easy handling of text and use of hypertext facilities were important criteria. This led to the choice of the Windows-based Guide program for the CAL authoring of Interpersonal Skills, with some Visual Basic add-ons for features requiring particular forms of representation or interactivity. For Research Methods, this was switched to use of a Visual Basic environment which accessed Guide text windows with the aim of achieving a more professionally designed product, a move from scrolling to paging, more integrated and systematic accessing of special features such as the Notebook, glossary and other add-ons, and a more promising development route for multimedia and extended graphics.

\section{Implementation}

Implementation has involved establishing test and trial sites within selected social-work courses for evaluating staff and student reactions to IPS. Other less formal feedback has been through demonstration at workshops and conferences. The programme for formal evaluation was initiated by a Training the Tutors event, at which social work educators proposing to introduce the module in their work with students were offered an intensive 24-hour orientation workshop. This proved invaluable in a number of respects in that it:

created a 'safe haven' for educators and ProCare staff to discuss the potential and limitations of IPS materials;

offered an opportunity for shared creative thinking on how to implement module-use in different settings and circumstances;

generated the basis of a tutor-use network for ongoing support and development.

Initial reactions to the IPS module have been encouraging, with important lessons learnt about content, structure, presentation, and how the program is used. Of particular interest have been the evaluation comments endorsing the project team's decision to provide a program requiring a low level of technology, and which appears to have been easy to install and maintain, both stand-alone and networked.

Currently, within test and trial sites, the primary focus has been on use of IPS as an additional learning resource rather than as a complete replacement for existing teaching. As TLTP materials are made available at no cost to UK higher-education institutions, this does not constitute a 'product acceptability' problem at this stage. However, it may 
become a critical issue if a move is made to offer ProCare materials on a more commercial basis; there, economic viability may well be determined, in large part, by its potential to replace rather than supplement teaching.

\section{References}

Adams, R. and Hopkins, T. (1996), 'Towards a systemic approach to the development of open and flexible learning environments: studies of implementation in the United Kingdom' in Fandel, G., Bartz, R. and Nickolmann, F. (eds), University Level Distance Education in Europe, Berlin, Deutscher Studien Verlag.

Centre for Human Service Technology (1996), Resources Guide: special issue of New Technology in the Human Services, 8 (4), CHST, University of Southampton.

Colombi, D.P., Rafferty, J. and Steyaert, J. (1993), Human Services and Information Technology: A European Perspective, ENITH (ISBN: 0-854-32476-3).

Glastonbury, B. and LaMendola, W. (1992), The Integrity of Intelligence - A Bill of Rights for the Information Age, Basingstoke, Macmillan.

Hopkins, T. (1995), 'Old wine in new bottles? Issues in CAL curriculum design', New Technology in the Human Services, 8 (2).

Hopkins, T. (1966), Using Open Learning in Social Work: A Guide to Implementation, Open Learning Foundation (in press).

Roosenboom, P. (1993), "The Dutch "National" Curriculum computer applications for schools of social work' in Liederman, M., Guzzetta, C., Struminger, L. and Monnickendam, M., Technology in People Services, New York, Haworth.

Seabury, B. (1993), 'Interactive video programs: crisis counselling and organisational assessment' in Liederman, M., Guzzetta, C., Struminger, L. and Monnickendam, M., Technology in People Services, New York, Haworth.

Schoech, D. (1990), Human Service Computing, New York, Haworth.

Schoech, D. (1996), 'Multimedia training for child protective social workers: results of initial development and testing' in Rafferty, J., Steyaert, J. and Colombi, D.P., The Human Services in the Information Age, New York, Haworth.

Storan, J. (1992), Credit Accumulation and Transfer for the Diploma in Social Work, CCETSW.

Steyaert, J., Colombi, D.P. and Rafferty, J. (1996), 'Human services and information technology: an international perspective', Arena (June).

Visser, A. (1996), 'Computers in education: added value leading towards better quality' in Rafferty, J., Steyaert, J. and Colombi, D.P., The Human Services in the Information Age, New York, Haworth.

Weinstein, J. (1994), Sewing the Seams of a Seamless Service, CCETSW.

Details of all computer programs referred to in the text are found in the Centre for Human Service Technology (1996), Resources Guide, referred to above. 